\title{
STUDY OF PHARMACY STUDENTS' ATTITUDES FOR SCIENTIFIC RESEARCHES AND/OR ACADEMIC CAREER IN BULGARIA
}

\author{
Ilko Getov, Hristina Lebanova, Valentina Belcheva, Evgeni Grigorov \\ Faculty of Pharmacy, Medical University of Sofia
}

\begin{abstract}
PURPOSE: To determine the attitudes towards participating in research projects among students at the Faculty of Pharmacy, Medical University Sofia.

MATERIAL AND METHODS: A questionnaire was devised and distributed during the final compulsory project meeting to the group of pharmacy students enrolled in the scientific project in the beginning of 2012-2013 academic year.

RESULTS: Among the 16 students included in the field research experiment study, 15 responded, with an overall response rate of $\mathbf{9 3 . 7 5 \%}$. Twenty percent of the students had previously participated in some form of research activity during their master degree education. Thirty three percent of all students surveyed expressed interest in participating in future research during their study and after graduation.

CONCLUSION: The pharmacy students sampled reported interest in research, with a minority of the students planning to participate in extracurricular research activities during their university education, and many hoping to be involved in research throughout their future career. However, only a small number of students were interested in pursuing research through completing a PhD program.
\end{abstract}

Keywords: pharmacy, student, attitude, scientific, project

\section{INTRODUCTION}

Balancing the academic values and the needs of market forces is not an easy task (8). In the last years there is an increasing emphasis placed on evidence-based medicine, pharmacotherapy and clin-

\footnotetext{
Address for correspondence:

prof. Ilko Getov, PhD

Medical University of Sofia,

Faculty of Pharmacy,

Department of Social Pharmacy,

2 Dunav Str., 1000 Sofia, Bulgaria,

Tel.: (+3592) 9236 587,

Fax: (+3592) 9879874 ,

e-mail:igetov@pharmfac.net
}

Received: October 7, 2014

Accepted: December 1, 2014 ical pharmacy and their application in scientific research (5). Advances in information technology allow rumors and misinformation to travel quickly, but also provide an enormous opportunity to facilitate the interaction and collaboration among physicians and pharmacists from different parts of the world (15). It is becoming very important for medical professionals to possess skills for understanding the scientific principles and methods, parallel to the training in acquisition and critical appraisal of new information and data $(2,7)$. Since its origin the concept for evidence-based medicine is accepted as a paradigm shift towards scientific-based clinical practice (3) and research experience, which emphasizes intellectual independence, helps to develop medical professionals and allows them easily to find a job $(4,19)$. 
Ilko Getov, Hristina Lebanova, Valentina Belcheva et al.

The most compelling reason for young people for choosing to study pharmacy at undergraduate level is because it is a science-based subject. However, caution was noted due to a possible misalignment between scientific career expectations and the social science involved in actual pharmacy practice (20). It is a challenge for pharmaceutical education to introduce more relative weighting of science within the study course (17). Increased efforts to recruit more individuals into academic careers must also be advocated (10).

In a recent study proceeded in the Medical University of Sofia, Markova et al. claimed that according to the students their access to scientific research is insufficient. The comparative analysis in their study showed that the percentage of students in medicine who evaluate positively the opportunity to participate in research activities is higher - nearly $40 \%$ (11).

Despite the recognized importance of supporting the scientific research of medical professionals in healthcare facilities, the economic analysis of the expenses in state and municipality hospitals in Bulgaria, made by Shtereva et al, showed a very modest level of financing these kind of activities (16). In another study from 2013, Stoynova et al. stated, that there is need for more money for promotional and educational materials supporting the adverse drug reactions reporting system (18).

Previous studies have suggested that academia and research organizations are becoming an unattractive career option for medical graduates worldwide. It has also been claimed, that exposure to research activities during medical school leads to interest in academic and research careers and greater scientific output after graduation $(6,9,14)$. Participation in scholarly activities and student authorship of a peer-reviewed journal manuscript during pharmacy school may lead to increased interest in a career in academic pharmacy (12). The attitudes of undergraduate medical students towards research might be influenced by a number of factors such as previous training and skills in research (1).

\section{MATERIAL AND METHODS}

All the respondents were students from the Faculty of Pharmacy, Medical University Sofia from different year of study. They were invited to participate anonymously in the survey. A special questionnaire was developed (adapted from Park et al. 2010) (13) with variety of questions focusing on research experience, attitudes towards research and long-term career intentions. The survey tool was validated on the basis of feedback from academic professor. The final questionnaire contained 10 items, which included tick box replies, 5-point Likert scalelike ranking, and additional free comment section. Questionnaires were distributed to students during the final compulsory project meeting of scientific project team in the middle of May 2013.

\section{RESULTS}

Demographic information and response rate Table 1 summarizes the demographic information of the respondents. Out of 16 students enrolled in the scientific project in the beginning of 20121013 academic year, 15 responded, with an overall response rate of $93.75 \%$.

Table 1. Demographic information of students

\begin{tabular}{lc}
\hline Variables & No. of students (\%) \\
Number of students & 15 \\
Mean age & 21 \\
Gender & \\
Male & $3(20)$ \\
Female & $12(80)$ \\
Year of study at Faculty of & \\
Pharmacy & \\
Year 2 & $1(7)$ \\
Year 3 & $5(33)$ \\
Year 4 & $7(47)$ \\
Year 5 & $2(13)$ \\
\hline
\end{tabular}

The mean age of respondents was 21 years (SD 1.3 years, range 19-23 years). Eighty percent were females and $20 \%$ males. The majority of respondents (47\%) were students from fourth year of study in master program "Pharmacy" at the University.

Research experience - Table 2 outlines whether the students have some previous research experience and their reasons for accepting to participate in a research project. 2 out of 15 respondents (13.33\%) reported being involved in some kind of research activities during their pharmacy education. Summer field scholarship (6.6\%) and "other research" 
Study of pharmacy students' attitudes for scientific researches and/or academic career in Bulgaria

Table 2. Research experience

\begin{tabular}{lc}
\begin{tabular}{l|c} 
Variables & No. of students \\
$(\%)$
\end{tabular} \\
$\begin{array}{l}\text { Number of students with research } \\
\text { experience }\end{array}$ & $2(13)$ \\
Research experience & \\
Summer scholarship & $1(7)$ \\
Other & $1(1)$ \\
Did participation in research & \\
increased interest in pursuing & \\
a career in research/academic & \\
pharmacy & \\
Agreed or strongly agreed & \\
Neutral & $4(27)$ \\
Disagreed or strongly disagreed & $4(27)$ \\
Interested in participating in \\
research during education \\
$\begin{array}{l}\text { Interested } \\
\text { Not interested }\end{array}$ \\
\hline \hline
\end{tabular}

experience $(6.6 \%)$ were the undertaken options included in the respondents' answers.

When students were asked whether their participation in research increased interest in pursuing a career in research/academic pharmacy or medicine, $27 \%$ agreed or strongly agreed with the statement, $27 \%$ were neutral and 56\% disagreed or strongly disagreed with the statement. However, $87 \%$ of all students surveyed were interested in participating in research during their university pharmacy education.

Attitudes towards scientific research at Faculty of Pharmacy - Table 3 summaries the students' responses to a set of statements designed to evaluate their attitudes towards research and research training during their education. The majority (62\%) of the respondents were affirmative of the statement that "laboratory-based scientific research was relevant to pharmacy practice." More than half (51\%) also

Table 3. Attitudes toward research and research training during medical school

\begin{tabular}{|lc|c|c|}
\hline & Negative \% & Affirmative \% & (disagree/ \\
Statement & (agree/strongly & Neutral \% & strongly \\
& agree) & disagree)
\end{tabular}

Research training should be a compulsory part of pharmacy school curriculum

26

62

Laboratory-based scientific research is relevant to pharmacy practice

Taking time off to do research is waste of time, if it does not advance my future career

Table 4. Research with respect to long-term career plan and specialty choice

\begin{tabular}{|l|c|c|c|}
\hline & Affirmative \% & Negative \% \\
(disagree/ & Neutral \% & strongly & disagree) \\
\hline
\end{tabular}

I plan to be involved in research throughout my medical career

I am interested in pursuing higher degree $(\mathrm{PhD})$ after graduation

Opportunity for research is an important consideration for me when choosing a specialty

Earning potential is an important consideration for me when choosing a specialty

Lifestyle is an important consideration for me when choosing a specialty
20

20

60

20

20

93

86
43

27

28
51

31

11 
Ilko Getov, Hristina Lebanova, Valentina Belcheva et al.

disagreed or strongly disagreed with the following statement: "Taking a year off from pharmacy school to do research is a waste of time, if it does not advance my future career." However, only $26 \%$ of the students responded positively to the idea of research training becoming a compulsory part of pharmaceutical education.

Long-term career plan and research - only one-fifth (20\%) of the pharmacy students sampled planned to be involved in research throughout their career. Three students (20\%) were interested in pursuing higher degrees ( $\mathrm{PhD}$ program) following graduation. Only $20 \%$ of students agreed or strongly agreed that opportunity for research was an important consideration when choosing a specialty.

In contrast, $84 \%$ of the respondents identified lifestyle and $43 \%$ identified earning potential as important considerations when choosing a specialty (Table 4).

\section{DISCUSSION}

One of the very encouraging findings is that $87 \%$ of the respondents expressed interest in participating in extracurricular research during their time of study at the Faculty of Pharmacy. Although more than 90 percent of the students revealed that "earning potential is an important consideration for them when choosing a specialty", there are $60 \%$ affirmative or neutral answers towards completing a $\mathrm{PhD}$ program after their graduation.

Interesting result is, that $62 \%$ of respondents think that "Laboratory-based scientific research is relevant to pharmacy practice" and this is their reason for participating in research activities, believing this can reflect to their future career.

It has been suggested that providing stimulation and opportunities for research during medical school may help to encourage medical students to pursue academic careers. In the current study, when asked whether participation in extracurricular research increased interest in careers in research or academic medicine or pharmacy, students' opinions were negative.

\section{CONCLUSION}

THE RESULTS OF THIS STUDY SHOW NEGATIVE TRENDS IN THE EXPECTATIONS for a future career of pharmacy students in Bulgaria in the scientific and academic fields. Some actions for raising a positive attitude among students for this kind of professional realizations are necessary to be done. A need to shift the focus of master degree training towards more "Laboratory-based scientific research" as well as promoting and providing diverse $\mathrm{PhD}$ programs at the faculty is important for the pharmacy students.

Acknowledgment: This study was a part of the Grant project 46/2012, funded by Medical University of Sofia.

\section{REFERENCES}

1. Burgoyne, L. N., S. O’Flynn, G. B. Boylan. Undergraduate medical research: the student perspective. Med. Educ. Online. 2010; No 15.

2. Byrne, E. The physician scientist: an endangered breed?-Intern. Med. J. 2004;34(3):75.

3. Darlenski, R. B., N. V. Neykov, V. D. Vlahov, N. K. Tsankov. Evidence-based medicine: Facts and controversies. Clin. Dermatol. 2010; 28(5):553-557.

4. Fisher, W. R. Medical student research: a program of self-education. J. Med. Educ. 1981;56(11):904-908.

5. Getov, I., E. Kostov, H. Lebanova, E. Grigorov. Clinical pharmacy - essence, progress and challenges in practice. Medical review. 2013;49(3):30-37 (in Bulgarian).

6. Goldacre, M., S. Stear, R. Richards, E. Sidebottom. Junior doctors' views about careers in academic medicine. Med Educ. 1999;33(5):318-326.

7. Hren, D., I. K. Lukic, A. Marusic, I. Vodopivec, A. Vujaklija, M. Hraba et al. Teaching research methodology in medical schools: students' attitudes towards and knowledge about science. Med Educ. 2004; 38(1):81-86.

8. Institutional Management in Higher Education. Academic values in the marketplace. -Higher Education Management and Policy. 2009;21(3):51-66.

9. Khadaroo, R. G., O. D. Rotstein. Are clinician-scientists an endangered species? Barriers to clinician-scientist training. Clin. Invest. Med. 2002; 25(6):260-261.

10. Maddux, M. S., B. J. Dong, W. A. Miller, K. M. Nelson, M. A. Raebel MA, C. L. Raehl et al. ACCP white paper: a vision of pharmacy's future roles, responsibilities and manpower needs in the United States. Pharmacotherapy. 2000;20(8): 991-1020. 
11. Markova, K., E. Vodenicharov, K. Popova, A.

Vodenicharova, P. Chavdarovski, K. Palaveev. Stu-

dents' participation in research projects - an op-

portunity for sensitizing them for ethical issuess.

Asklepios. 2013;7(1):46-50 (in Bulgarian).

12. Nykamp, D., J. E. Murphy, L.L. Marshall, A. Bell. Pharmacy students' participation in a research experience culminating in journal publication. Am. J. Pharm. Educ. 2010;74(3):47.

13. Park, S.J., C. N. McGhee, T. Sherwin. Medical students' attitudes towards research and a career in research: an Auckland, New Zealand study. N. Z. Med. J. 2010;123(1323):34-42.

14. Reinders, J.J., T. J. Kropmans, J. Cohen-Schotanus. Extracurricular research experience of medical students and their scientific output after graduation. Med. Educ. 2005;39(2):237.

15. Rath, B., M. Ali, G. Codarini, C. Elemuwa, A. Khamesipour, W. Maurer et al. Promoting evidence-based vaccine safety research and communication--the Vienna Vaccine Safety Initiative. J.Trop. Pediatr. 2012; 58(3):167-169.

16. Shtereva, D. T., A. Gladilova, E. Naseva, A. Cheshmedjieva. Economical analysis of the expenses of state and municipality hospitals in Bulgaria. J. Int. Sci. Pub.: Economy \& Business, 2012; 6(1):202-211.

17. Sosabowski, M. H., P. R. Gard. Pharmacy Education in the United Kingdom. Am. J. Pharm. Educ. 2008;72(6):130.

18. Stoynova, V., I. N. Getov, E. K. Naseva, H. V. Lebanova, E. E. Grigorov. Physicians' knowledge and attitude towards adverse event reporting system and result to intervention--randomized nested trial among Bulgarian physicians. Med. Glas. (Zenica). 2013;10(2):365-372.

19. Vekov, T. The medical doctors opinion regarding healthcare reform in Bulgaria. World Hospitals and Health Services. 2009;45(1):9-14.

20. Willis, S.C., P. Shannon, K. Hassell. Who will be tomorrow's pharmacists and why did they study pharmacy? The Pharmaceutical Journal. 2006; 277(7410):107-108. 